\title{
A BEME systematic review of the effects of interprofessional education: \\ BEME Guide No. 39
}

\author{
Scott Reeves (1) \\ Simon Fletcher (1) \\ Hugh Barr (2) \\ Ivan Birch (3) \\ Sylvain Boet (4) \\ Nigel Davies (5) \\ Angus McFadyen (6) \\ Josette Rivera (7) \\ Simon Kitto (4)
}

(1) Kingston University and St George's, University of London, UK

(2) Centre for the Advancement of Interprofessional Education, UK

(3) Sheffield Teaching Hospitals NHS Foundation Trust, UK

(4) Faculty of Medicine, University of Ottawa, Canada

(5) University of Bedfordshire, UK

(6) AKM-STATS, Scotland, UK

(7) University of California, San Francisco, USA

\footnotetext{
Corresponding author

Professor Scott Reeves

Centre for Health \& Social Care Research

Kingston University \& St George's, University of London

St George's Hospital, Cranmer Terrace, London, SW17 OBE, UK

s.reeves@sgul.kingston.ac.uk

This is an Accepted Manuscript of an article published by Taylor \& Francis in Medical Teacher on 5 May 2016, available online: http://
} www.tandfonline.com/10.3109/0142159x.2016.1173663. 


\begin{abstract}
Background: Interprofessional education (IPE) aims to bring together different professionals to learn with, from and about one another in order to collaborate more effectively in the delivery of safe, high quality care for patients/clients. Given its potential for improving collaboration and care delivery, there have been repeated calls for the wider scale implementation of IPE across education and clinical settings. Increasingly, a range of IPE initiatives are being implemented and evaluated which are adding to the growth of evidence for this form of education.
\end{abstract}

Aim: The overall aim of this review is to update a previous BEME review published in 2007. In doing so, this update sought to synthesise the evolving nature of the IPE evidence.

Methods: Medline, CINAHL, BEI and ASSIA were searched from May 2005 to June 2014. Also, journal hand searches were undertaken. All potential abstracts and papers were screened by pairs of reviewers to determine inclusion. All included papers were assessed for methodological quality and those deemed as 'high quality' were included. The presageprocess-product (3P) model and a modified Kirkpatrick model were employed to analyse and synthesise the included studies.

Results: Twenty-five new IPE studies were included in this update. These studies were added to the 21 studies from the previous review to form a complete data set of 46 high quality IPE studies. In relation to the 3P model, overall the updated review found that most of the presage and process factors identified from the previous review were further supported in the newer studies. In regards to the products (outcomes) reported, the results from this review continue to show far more positive than neutral or mixed outcomes reported in the included studies. Based on the modified Kirkpatrick model, the included studies suggest that learners respond well to IPE, their attitudes and perceptions of one another improve, and they report increases in collaborative knowledge and skills. There is more limited, but growing, evidence related to changes in behaviour, organisational practice and benefits to patients/clients.

Conclusions: This updated review found that key context (presage) and process factors reported in the previous review continue to have resonance on the delivery of IPE. In addition, the newer studies have provided further evidence for the effects on IPE related to a number of different outcomes. Based on these conclusions, a series of key implications for the development of IPE are offered.

\title{
Introduction
}

Interprofessional education (IPE) continues to be invoked nationally and internationally by policy makers, health and social care professionals and educators as a means to improve collaboration and service delivery (e.g. WHO 2010, IOM 2015). It is argued that if individuals from different professions learn with, from and about one another they will work better together to improve the service they deliver to patients/clients.

IPE has been defined as "occasions when two or more health/social care professions learn with, from and about each other to improve collaboration and the quality of care" (CAIPE, 2002). IPE aims to enhance attitudes, knowledge, skills and behaviours for collaborative practice, which in turn can make improvements to clinical practice. In doing so, it is 
anticipated that IPE can improve the quality of care delivered to patients/clients (Brandt et al 2014; Fung et al. 2015).

National and international policymakers have repeatedly called for the use of IPE to better prepare health and social care learners to enter the workplace as an effective collaborator (Frenk et al. 2010; WHO 2010; IOM 2015). As a result, IPE is increasingly being offered across health and social care sectors to an array of learners (pre-qualification, post qualification, continuing education) based in classrooms, simulation labs, clinical settings and increasingly through online (virtual) environments (e.g. Luke et al. 2010; Bridges et al. 2011; Palaganas et al. 2014).

From this growing amount of empirical work, it is possible to see that IPE can have a beneficial impact on learners' attitudes, knowledge, skills and behaviours - also termed as collaborative competencies (Abu-Rish et al. 2012; Makino et al., 2013). In addition, evidence is growing which suggests that IPE can also positively affect the professional practice as well as improve clinical outcomes (Kent \& Keating 2013; Reeves et al. 2013).

Given this sustained growth of IPE activity, repeated policy calls and expanding evidence it was considered timely to update an earlier BEME IPE systematic review (Hammick et al 2007 - see Box 1 for key findings) to identify whether there were additional studies that meet the BEME criteria which can inform the IPE evidence base. An important part of updating this review was to synthesize the best available contemporary evidence to help shape future design, delivery and evaluation of IPE.

\section{Box 1: Key findings from the initial BEME Review}

- IPE is generally well received by participants, can support improvements in attitudes and can enable them to develop the knowledge and skills needed for collaborative working. However, there is less evidence for the effects of IPE on individuals' behaviour and service delivery.

- IPE can be used as a mechanism to enhance the development of practice and improvement of services.

- Participants bring unique values about themselves and others into any IPE event which then interact in a complex way with the mechanisms that influence the delivery of the educational event.

- Authenticity and customisation of IPE so that it reflects appropriate and relevant service delivery settings are important mechanisms for a positive experience for the participants.

- Principles of adult learning for IPE are key mechanisms for well received IPE.

- Faculty development is needed to enable competent and confident facilitation of IPE. 


\section{Methods}

\section{Aims and objectives}

The overall aim of this review was to update a previous BEME review completed by Hammick et al. (2007). In doing so, the specific objective of the review was to consider the effectiveness of different types of IPE interventions on a range of outcomes, including impact on the knowledge, skills and attitudes of the learner, and subsequent change in organisational practice and/or benefits to patients/clients.

\section{Types of intervention}

An IPE intervention was defined as: when members of more than one health and/or social care profession learn interactively together, for the explicit purpose of improving the health or well-being of patients/clients. Interactive learning requires active learner participation, and active exchange between learners from different professions.

\section{Types of participants}

Among the professional health and social care groups included were the following: chiropodist/podiatrist, complementary therapists, dentists, dieticians, doctors (physicians, surgeons, anaesthetists), hygienists, paramedics, psychologists, psychotherapists, midwives, nurses, pharmacists, physiotherapists, occupational therapists, radiographers, speech therapists, social workers, assistant practitioners, care/case co-ordinators and managers.

\section{Types of studies}

All research evaluation designs (e.g. action research, case study, ethnographic, experimental, quasi-experimental studies) were included in this update.

\section{Types of outcome measures}

Outcome measures were based on Barr and colleagues' (2005) extended version of Kirkpatrick's classic educational outcomes model, which has six differing but nonhierarchical levels, as outlined below:

Level 1 -Reaction: these cover learners' general views and perspectives on the learning experience, its organisation, presentation, content, teaching methods and aspects of the institutional organisation, e.g. time-tabling, materials, quality of teaching.

Level $2 a$-Modification of attitudes/perceptions: these outcomes relate to changes in reciprocal interprofessional attitudes or perceptions between participant groups, towards patients/clients and their conditions, circumstances, care and treatment.

Level $2 b-$ Acquisition of knowledge/skills: for knowledge, this relates to the acquisition of concepts, procedures and principles of interprofessional collaboration. For skills, this relates to the acquisition of thinking/problem-solving, psychomotor and social skills linked to collaboration.

Level 3 -Behavioural change: this measurement documents transfer of interprofessional skills and learning to workplace, such as support for change of behaviour in the workplace or willingness of learners to apply new knowledge and skills about collaborative work to their practice style. 
Level $4 a$-Change in organisational practice: this relates to wider changes in the organisation/delivery of care, attributable to an education programme, such as, changes in organisational policies or clinical pathways that promote interprofessional collaboration, communication, teamwork and co-operative practice.

Level $4 b$-Benefits to patients/clients: this level covers any improvements in the health and well-being of patients/clients as a direct result of an IPE programme. Where possible, such as, health status measures, disease incidence, duration or cure rates, mortality, complication rates, readmission rates, adherence rates, patient or family satisfaction, continuity of care, costs to carer or patient/client.

\section{Search strategy}

To update the previous BEME review (which searched for literature up to April 2005), this review searched the following electronic databases: Medline, CINAHL, BEI and ASSIA from May 2005 to June 2014. Papers published in English or French were included.

Electronic Databases: A standard search strategy was used, based on the one used for the previous BEME review. As with all reviews, due to variations in how each of the electronic databases employ key terms, this search strategy was adapted for each electronic database and aimed at identifying all types of IPE interventions (See Appendix 1, available online as supplementary material).

Other searches: Hand searches of interprofessional journals (Journal of Interprofessional Care, Journal of Research in Interprofessional Practice and Education, Health and Interprofessional Practice) published from May 2005 to June 2014 were also undertaken.

\section{Screening and inclusion/exclusion criteria}

All abstracts and titles generated from these searches (3,387 abstracts) were reviewed independently by two members of the review team to determine if they met our inclusion criteria (see above). The full text article was obtained (392 papers) if the abstract met these criteria. These articles were screened independently by two reviewers to determine if they met the inclusion criteria. This resulted in 258 papers which underwent a quality assessment (see below). Papers which were deemed 'low quality' were excluded from the review. This resulted in the inclusion of a final set of 25 'high quality' IPE studies. Figure 1 (found online as supplementary material summarises the search processes and outcomes.

\section{Quality assessment}

As noted previously all 258 provisionally included papers were quality assessed independently by two members of the review team. Like the previous review, two quality scores were allocated to each study to support the selection of well-designed and clearly reported IPE studies. In particular, we distinguished between 'quality of study' and 'quality of information'. The quality of study score reflected the design and execution of the study. This covered, for example, a good fit between the methodological approach and research questions, attention to ethical issues and appropriate analysis and inferences. The quality of information score covered elements such as a clear rationale for an IPE intervention and its 
evaluation, good contextual information, sufficient information on sampling, ethics and the identification of possible bias.

Following the procedure outlined in the previous review, each of the two quality scores had an ascending five-point scale and only studies attaining at least four on both dimensions were eligible for inclusion in this update. The use of this approach aimed to identify the strongest IPE studies available, ensuring that all study designs (whether quantitative and/or qualitative in nature) were judged in an equitable manner. (For further information about this process see our BEME review protocol: http://bemecollaboration.org/)

\section{Data extraction}

Key data extracted from all the included papers from this update were used in the production of a descriptive summary. Following the data abstraction described in the previous review, this data extraction process aimed to generate basic descriptive information from each paper in the following three areas:

- Nature of the IPE initiative (e.g. educational aims/objectives, duration, professional participants)

- Reported outcomes (e.g. learner reactions, acquisition of knowledge/skills, changes in individual behaviours)

- Methods of evaluation (e.g. research designs, data collection methods, approaches to analysis, sampling)

To ensure consistency two members of the team (SR, SF) independently coded a sample of around $20 \%$ of the papers from the updated search into the data abstraction sheets. Discussion occurred around a few discrepancies identified in this process due to small differences in interpretation related to reported information in the included papers. Agreement was achieved with all papers.

\section{Analysis and synthesis}

Due to the heterogeneity of IPE interventions (differing curriculum content, duration of courses, participating professional groups) and study designs (quasi-experimental, exploratory, action-orientated) a meta-analysis of studies was not possible. Therefore, the 25 studies identified from the updated search were added to the existing 21 studies to form a single narrative of all included studies. While this narrative approach to analysis and synthesis meant that the review could accommodate the diverse nature of the 46 IPE evaluations (Mays et al., 2005), it does contrast with more traditional meta-analytical techniques. Nevertheless, the review can provide some pragmatic implications to inform the future development and delivery of IPE for educators, researchers and policy makers.

Like the previous review, the update employed Biggs' (1993) presage-process-product (3P) model of learning and teaching to understand IPE research in relation to contextual factors, educational processes and associated outcomes. This model of learning and teaching was devised by Biggs (1993) who saw 'presage factors' as the socio-political context for education and the characteristics of the individuals (planners, teachers and learners) who participate in learning/teaching. 'Process factors' were seen as the approaches to learning and teaching that were employed in an educational experience and 'product factors' were seen as the outcomes of the learning. Figure 2 (available online as supplementary material) 
provides an outline of a slightly revised version model which was previously modified for an IPE analysis.

The 3P model was employed as an analytical framework to synthesise data from all the included studies. This work involved coding extracted information from the updated papers into the appropriate presage, process and product sections of the model. In regards to the nature of this work, one reviewer initially distilled abstracted information from the 25 new papers which mapped onto the 3P model as described in the initial review. This involved adding information into the presage, process, product sections with extracted information and creating subheadings and extra categories as needed. As this analytical work proceeded it was regularly discussed between two members of the review team involved in the abstraction process to ensure consensus before sharing with the wider group for final agreement. Based on this work, a final synthesised narrative of the included studies linking IPE presage with IPE processes and products was generated.

\section{Results}

Twenty-five studies were found as a result of the updated searches. These studies were added to the 21 studies reported in the previous review, forming a total of 46 included IPE studies. Results from the analysis and synthesis of Results from the analysis and synthesis of these papers are presented in a narrative supported by descriptive statistics where relevant. The results are presented in two main sections: an overview of the included studies, followed by results from the 3P synthesis.

\section{Overview of included studies}

Table 1 (, available online as supplementary material) summarizes the 46 studies. As indicated in this table, these studies were published between 1981 and 2014, with the majority published in the last 15 years. The majority of studies $(57 \%)$ were undertaken in Europe (19 UK, 2 The Netherlands, 2 Denmark, 1 Finland, 1 Germany, 1 Sweden), with 17 studies (37\%) undertaken in North America (10 USA, 7 Canada) and 3 studies (6\%) undertaken in Australia.

Just over half of the studies ( $n=25)$ evaluated IPE delivered to undergraduate health professions students. Eighteen studies (39\%) evaluated IPE at in-service continuing professional development (CPD) level. In addition, one study was a university-based postgraduate course while two studies evaluated IPE with a mixture of learners - one study with pre-qualification students and qualified staff and the other study with nursing students and medical residents (trainees).

In terms of professional participation, medicine and nursing are the two professions who most frequently share their IPE experiences together (33 studies, 72\%). Together these two professions were most likely to share their IPE with learners from social work ( 21 studies, $46 \%$ ), occupational therapy (18 studies, 39\%), physiotherapy (17 studies, 37\%), with other professional groups (e.g. pharmacy, radiography, speech and language therapy) appearing less often. In general, studies included between two to six professions. However, there were a small number of studies that included a wider professional mix: over 20 different professions groups (Curran et al 2007), 17 groups (Byrnes et al. 2012) and 13 groups (Watts et al 2007). 
In terms of evaluation methods, most studies ( $n=36,78 \%$ ) employed experimental or quasiexperimental designs, usually a controlled before-and-after or before-and-after design. In contrast, only five studies (11\%) employed qualitative designs. The majority of studies $(n=27,58 \%)$ gathered a single method of data collection: surveys ( $n=22,47 \%)$; clinical audit data $(n=5,11 \%)$ and interviews ( $n=1)$. In contrast, 19 studies (41\%) gathered a mix of data sets, most typically in the form of surveys and interviews. Fourteen studies (30\%) employed a longitudinal design, most often gathering data at three points in time (before-and-after the IPE course, with a third data collection point occurring a few weeks or months after). In contrast, a small number of studies gathered data over a longer period. For example, Pollard et al. (2006), Pollard \& Miers (2008) and McFadyen et al. (2010) collected data over a fouryear period.

\section{Presage, process and product synthesis}

As noted previously, this update aimed to build on the findings reported in the previous review which found a number of 3P elements of importance in shaping the nature of IPE for the studies. Below we report how the inclusion of the 25 studies from the update have affected the contents of the 3P model. In particular, we note where the papers from the updated search have either reinforced the model or where new elements have been identified.

\section{Presage Factors}

In relation to presage factors the previous review reported that a range of elements linked to IPE context, learner characteristics and teacher characteristics were of importance. Later we report on these elements of presage and how they may affect the delivery of IPE.

\section{IPE context}

The previous review found contextual issues that influenced the development and implementation of IPE were linked to policy and clinical drivers for IPE (Cooke et al. 2003; Tucker et al. 2003), organisational support to provide access to resources, such as time, space and finances (e.g. Morey et al. 2002) and learner professions/numbers (Mu et al. 2004). After the synthesis of the new studies with the previous studies, it was found that the focus on these presage factors were critical in both the development and successful sustainability of IPE.

In particular, the updated papers continued to emphasise that the development of IPE was linked to a desire to improve patient care or service delivery through improvement in interprofessional collaboration and teamwork (Carpenter et al. 2006; Curran et al. 2007; Watts et al. 2007; Quinn et al. 2008; Fuhrmann et al. 2009; Robben et al. 2012; Slater et al. 2012; Paquette-Warren et al. 2014). Again, these drivers were identified as linked to either top-down (e.g. government policies, professional regulators) or bottom-up (e.g. local IPE champions, organisational support) approaches (Curran et al. 2007; Richardson et al. 2010). Often, it was reported that a mixture of these two drivers was particularly effective in providing the incentive to implement an IPE activity (e.g. Hobgood et al. 2010; Slater et al. 2012). 
A number of the updated papers also continued to stress the key role of local organisational support (e.g. Curran et al. 2007; Hobgood et al. 2010). Fuhrmann et al (2009) noted that there was support from across their clinical institution when implementing a simulated IPE experience, and that a 'bottom-up' approach (only involving educators) would be likely to fail. They state, "commitment from institutional leadership on all levels was essential" to the successful delivery of this IPE initiative (p1359). This point was stressed by Richardson et al (2010), who reported, "educational leaders and administrators and not just the educators need to be committed to the [IPE] project" (p43). Both these studies noted that such institutional support is critical in ensuring access to resources for the development and implementation of IPE. Visser \& Wysmans (2010) effectively illuminate this point in their description of how the loss of a local IPE leader (and champion) resulted in the failure of their hospital-based IPE initiative. They stated, "the new department's head did not have the same inspiration and experience and had other policy priorities" ( $\mathrm{p} 406)$.

Where limited organisational support was noted in studies, this usually resulted in problems accessing resources such as time, space and finances for IPE. For example, as Slater et al (2012) noted, "time was identified as the main barrier to effective participation" (p85). To overcome this problem, these authors reported how they offered their IPE workshops on weekends. However, they note that this 'out-of-hours' IPE resulted in an unexpected beneficial outcome, "there was more time for personal meetings with colleagues as the work pressure was absent." For Nesbit et al. (2008) the lack of support for their interprofessional student placement meant it was an 'add-on' educational activity in their curriculum. This resulted in challenges to its implementation which included, "aligning clinical placement timetables to enable a range of professions to participate; [...] incorporating IPE activities into an already crowded clinical placement curriculum; and ensuring that key stakeholders were involved in development and implementation of the program" (p66).

In relation to funding, in total 30 studies (65\%) acknowledged specific external project funding to develop/evaluate the IPE (13 studies from the previous review, 17 from the updated search). External funding is an important source of support for developing and evaluating IPE but the time limited nature of such sources continues to challenge efforts to successfully sustain IPE activities within normal budgets. Mindful of this issue, a number of the studies (e.g. Curran et al 2007; Nesbit et al. 2008; Hollenberg et al. 2009; Visser \& Wysmans 2010) outlined ideas for successfully sustaining IPE, noting factors like organisational 'buy-in' to ensure dedicated resources as well as developing partnerships between educational and clinical providers.

Like the previous review, issues related to learner professions and numbers continued to influence the delivery of IPE. Within a pre-qualification IPE context, there was often a need to involve large cohorts of students. For instance, Pollard \& Miers (2008) evaluated IPE delivered to over 400 students from six professions, and McFadyen et al (2010) evaluated an IPE programme delivered to over 300 students from seven professions. In a postqualification, one study reported providing IPE workshop to over 3,500 health, social care and education practitioners across four Canadian provinces (Curran et al 2007). However, as noted above, most studies tended to include around 2 to 6 different professions with 
numbers usually ranging from 30-100 learners (e.g. Ammentorp et al. 2007; Just et al 2010; Richardson et al. 2010).

Like the previous review, there was again no information related to how contextual elements linked to geography and demography (age, gender and ethnicity) might affect an IPE programme, although we return to gender and age later in the section on 'learner characteristics'.

\section{Teacher characteristics}

The previous review identified the quality of the facilitation (e.g. Ponzer et al. 2004) and the need for faculty development for facilitators (e.g. Morison et al. 2003) as two key elements of this presage factor. Again, there was little attention placed on this factor in the updated papers. Of the handful of papers that did address teacher characteristics, they reemphasised the importance of both the quality of facilitation during an IPE experience and that facilitators need faculty development to ensure they can be as effective as possible in their facilitation work.

In terms of quality of facilitation, LeFlore et al (2009) reported that IPE facilitators were critical to the success of their IPE initiative. They stated that the facilitators ensured that interprofessional learning environments were conducive and non-threatening for students which helped maximise their collaborative learning experiences. Similarly, for Watts et al. (2007) the role of the IPE facilitator was "vital to the success" (p447) of their IPE programme. Again, these authors noted the central role of the facilitator in creating a climate of safety and confidence among learners. Watts and colleagues also reported that facilitators were key to the IPE experience in setting realistic goals, motivating learners, managing interactions to ensure equal participation, minimising possible interprofessional friction as well as "ensuring that all those taking part felt equally valued and empowered" (p447).

Other authors reported the need for faculty development for IPE facilitators to develop high-level skills (Pollard et al. 2006; Ammentorp et al. 2007; Curran et al. 2007). For example, Richardson et al (2010) reported that facilitators needed faculty development opportunities to ensure they have an understanding of educational theory linked to supporting collaborative social learning, ethical student development as well as the development of learners as reflective practitioners.

\section{Learner characteristics}

The previous review found a number of issues connected to learner characteristics, specifically, attitudes to IPE (e.g. Carpenter 1995), willingness to participate in IPE (e.g. Morison et al. 2003), professional stereotypes and hierarchies (e.g. Cooke et al. 2003), gender (e.g. Pollard et al. 2005), age, work experience and professional background (e.g. Tucker et al. 2003) could affect the delivery of IPE.

The findings from the updated search revealed that these elements of presage were still of significance in the newer IPE studies. The influence of learner attitudes towards IPE was reported in a number of studies (e.g. Pollard et al. 2006; Bradley et al. 2009; Byrnes et al. 2012). In general, it was reported that learners entered their respective IPE programmes 
and courses with positive attitudes, which would often diminish after participation in their respective interprofessional learning activities. Although, as McFadyen et al. (2010) report from their longitudinal controlled study, "pre-registration health and social care students commence their pre-registration education with strong positive views supporting the principles behind IPE. They also confirm that these levels may however initially be rather idealistic" (p562). The existence of poorer attitudes towards IPE was also noted by Just et al. (2010) who reported that students with such attitudes, "tend to gain the least from IPE courses" (p194). A key element in the formation of these different attitudes towards IPE was seen as the professional socialisation processes (e.g. Pollard et al 2006), but as reported below, prior work experiences, age and gender were also identified as important learner characteristics.

Willingness to participate in IPE also was regarded as a key learner characteristic in the newer studies. In general, it was found that IPE participation was a voluntary activity (e.g. Watts et al. 2007; Nesbit et al 2008; Hollenberg et al. 2009; Byrnes et al. 2012). As a result, learners who self-selected for IPE were regarded as motivated to learn in a collaborative manner with learners from other professional groups. To ensure learner IPE readiness and motivation, Carpenter et al (2006) reported that selection into a postgraduate IPE course for mental health providers was by application form and interview so that "students were required to demonstrate their academic readiness for postgraduate education and commitment to the aims of the programme" (p151). In contrast, reluctance to participate in IPE was often linked to issues such as clashes with profession-specific learning activities, work pressures or inequalities in assessment (e.g. Morison et al. 2003; Nisbet et al 2008).

The existence of professional stereotypes and hierarchies was another learner characteristic reported in the newer studies. Bradley et al. (2009), for example, reported that students in their IPE evaluation arrived with preconceptions about imbalances in hierarchy and status which did result in some negative stereotyping. In particular, these authors noted how some nursing students linked their view of medical undergraduates with "stereotypical representations of doctors' roles, status and behaviours" (p918). Similarly, Carpenter et al. (2006) reported that "there was considerable evidence of professional stereotyping but little evidence of change in these stereotypes during the programme. Positive stereotypes were not strengthened appreciably, nor were negative stereotypes reduced" (p153). Nevertheless, these authors note that despite these views, students still interacted together in a positive interprofessional manner. Carpenter and colleagues go on to suggest that this was because learners regarded their fellow participants on the programme as atypical of the members of the professions for which they maintained their traditional stereotypical views. Findings reported by Nesbit et al (2008) support this view of professional stereotyping, "somewhat disturbing were negative attitudes expressed by some students towards doctors [...] were not always reversed by the end of the program, and in some cases, were reinforced [...] comments regarding doctors were generally directed at practising medical staff rather than students, suggesting that role models within the workplace have a significant influence" (p66).

The existence of professional hierarchies was also reported in a number of the studies (Watts et al 2007; Nisbet et al. 2008; Pollard \& Miers, 2008). For instance, Bradley et al (2009) provide an insightful account of this issue in their evaluation of an IPE course for 
undergraduate nursing and medical students. They report that some of the nursing students in their study "were worried about hierarchical relationships" which were "attributed to hierarchical views of medical power combined with poor knowledge of or subordinate views of the nurse's role" (p917). These authors go on to note that despite these views, attitudes improved significantly after the students' involvement in their IPE course. However, it was noted that attitudes returned to pre-IPE levels after a period of around four months.

The previous review reported how the learner characteristics of age, previous work experience and profession could affected the delivery of IPE. These factors were again present in the updated review, but only in a small number of IPE evaluations involving undergraduate students. In their longitudinal studies involving many hundreds of prequalification students Pollard et al (2006) and Pollard \& Miers (2008) reported previous experience had influenced their perspective concerning IPE. For example, Pollard et al (2006) noted that previous experience for some students as health care assistants might foster poorer perceptions of interprofessional interaction with students from professional groups which were viewed as having a higher status. Learner age was another factor considered to be influential on IPE for undergraduate students (e.g. McFadyen et al. 2010) with younger students being, in the main, more positive about their interprofessional relationships. However, despite their more negative views, Pollard \& Miers (2008) reported that the older students played a more active role than younger members, with the oldest students being most participative.

Gender as a learner characteristic was reported in a small number of studies. Although whereas as Pollard et al (2006) reported that female students were comparatively positive about IPE in their longitudinal study of undergraduate students attitudes, other studies reported that gender did not have any noticeable effect on the delivery of IPE (Bradley et al. 2009; McFadyen et al 2010). In their later study, Pollard \& Miers (2008) found that there were no significant differences in scale scores on the basis of gender.

\section{Process Factors}

The previous review identified a number of teaching and learning process factors which affected the delivery of IPE. For example, encouraging facilitators to reflect regularly upon their IPE experiences (e.g. Morey et al. 2002) as well as offering coaching and mentoring opportunities to learners were found to be of importance. In addition, curricular design issues linked to learner choice (e.g. Shafer et al. 2002), customisation and authenticity of the IPE (Cooke et al. 2003), use of reflection (e.g. Barber et al. 1997) and informal learning opportunities in IPE (e.g. Nash \& Hoy 1993) were also found to be influential.

Although a number of studies made mention of the process of IPE facilitation (e.g. Hollenberg et al 2009; Just et al. 2010), most studies paid little attention to this issue. The one exception was LeFlore et al. (2009) who compared facilitated debriefing with selfdirected learning by students after team simulated clinical scenarios. These authors found that facilitator debriefing was more effective than self-directed learning, and note the key influence of the facilitator in ensuring effective interprofessional interactions.

While the issue of regular reflection for facilitators was not found in the newer studies, the facilitators' role in coaching IPE learners was re-emphasised. Both Slater et al. (2012) and 
Paquette-Warren et al. (2014) reported how IPE facilitators coached their respective teams of interprofessional learners in person, on the telephone and via email to keep learners (clinical staff) motivated during their involvement in quality improvement initiatives. At the undergraduate level, two studies (Hobgood et al. 2010; LeFlore et al. 2009) reported how facilitators extended their role during interprofessional simulation activities not only to prepare the simulated scenario and undertake the subsequent debrief, but to play a 'confederate' role in the scenarios to ensure effective interactions during the scenario.

More attention was given to learning processes in the updated studies. In relation to learner choice, whereas the previous review found that IPE for post-qualification learners was generally a voluntary activity, for undergraduate learners it was more mixed (compulsory for some students and voluntary for others). The updated studies revealed a slightly different situation - while IPE remained voluntary for post-qualification learners (e.g. Robben et al 2012), there was more equality at the undergraduate level, as IPE was either voluntary (e.g. Shiyanbola et al. 2014) or compulsory (e.g. McFadyen et al 2010) for all student groups.

Learner participation in the curriculum design was, like the previous review, also limited. Often, an IPE course would be developed by a project steering group or curriculum development committee (Just et al. 2010; Lineker et al. 2012; Anderson \& Thorpe 2014) who at times, worked with other stakeholders such as healthcare providers, researchers, and/or patients (e.g. Hollenberg et al. 2009; Byrnes et al 2012).

In relation to the issue of customisation, a range of activities were described in the newer papers. To ensure post-qualification IPE could meet local clinician staff needs, many studies reported that the courses were tailored (customised) to meet these needs (e.g. Fuhrmann et al 2009; Visser \& Wysmans, 2010; Lineker et al 2012). Two studies (Curran et al. 2007; Paquette-Warren et al. 2014) reported undertaking more extensive needs assessments activities. For Curran and colleagues, this involved a large study of "health care providers across the four [Canadian] provinces using a mix of survey questionnaires, interviews, and focus groups" (p243). As well as undertaking an initial needs assessment, Paquette-Warren and colleagues also report that their IPE course "was modified during implementation to better address the needs of participants" (p237).

Customisation of IPE to maximise learning opportunities covered a range of different elements, such as ensuring that the delivery mode of IPE sessions were modified to improve attendance from busy clinical staff (e.g. Quinn et al. 2008), providing financial compensation for the hours spent attending IPE workshops (e.g. Robben et al. 2012), and offering IPE sessions across different locations to ensure learner engagement and interaction (Carpenter et al. 2006). However, as Pollard et al (2006) note, customising IPE for the needs of different learner groups is problematic due to the varying range of characteristics, abilities and professional viewpoints among students undertaking IPE.

Given that post-qualification IPE developed as a response to a local clinical need, as noted above, issues of authenticity were not discussed in these studies. In contrast, this issue was in more evidence within the undergraduate IPE studies, as learners demand that their IPE was realistic in nature and so reflected clinical practice. For example, Bradley et al. (2009) noted the use of "resuscitation skills learning may have been seen as contextually important 
to both groups [medical/nursing students] and the shared outcomes promote IPE as a concept and as a practical implementation" (p920). As a result of this focus, Bradley and colleagues noted that the IPE was regarded as more authentic in nature. Similarly, Nisbet et al. (2008) reported that real life (authentic) experiences on clinical ward for undergraduate students "encouraged a team approach and collaboration through real experience, and that it improved student confidence in communicating within a multidisciplinary team" (p65).

Like the previous review, a number of studies from the updated searches reported the use of shared reflection for learners across undergraduate and post-qualification studies (Pollard et al. 2006; Hollenberg et al. 2009). Usually, reflection on learning processes occurred at the end of an IPE session (Nesbit et al 2008), although for Richardson et al. (2010) reflection upon interprofessional learning processes was undertaken by use of student journals. In contrast, only three studies mentioned the use of informal learning (Carpenter et al. 2006; Pollard \& Miers, 2008; Fletcher et al. 2014). For Carpenter and colleagues, it was noted that "students welcomed the many formal and informal opportunities provided by the programme to exchange ideas and experiences with colleagues from other disciplines and from other mental health services in the region" (p153), whereas Fletcher and colleagues, noted that clinicians "particularly appreciated opportunities for informal networking and learning about the availability and expertise of local mental health professionals" (p38).

It was found that most studies did not mention those that explicitly employed a theory in the delivery of their IPE course or activity. In general, these studies drew implicitly adult learning theories developed by Knowles (1975), Kolb (1984) and Schön (1983). However, 12 studies employed quality improvement principles in the delivery of practice-based IPE (e.g. Ketola et al. 2000; Slater et al., 2012). In addition, two studies employed the socialpsychological perspective, contact theory (Carpenter 1995; Carpenter \& Hewstone 1996), two studies (Ammentorp et al. 2007; Robben et al., 2012) employed social cognitive perspectives developed by Bandura (1977; 2004), one study (Richardson et al., 2010) employed elements an approach described by Clarke (2005) which incorporated five complementary learning perspectives, and one study (Anderson \& Thorpe, 2014) employed constructivist learning principles and reflection (Vygostsky 1978; Kolb 1984) in the delivery of their IPE activity.

\section{Product Factors}

As outlined in Figure 2, the key products linked to IPE range from reactions to the learning experience (level 1), changes in perceptions/attitudes (level 2a), acquisition of collaborative knowledge/skills (level 2b), changes in individual behaviour (level 3), changes to service delivery (level 4a) and improvements to patient/client care (level 4b). Below, we report outcome data across these six types of outcomes. This is summarized in Table 2. 
Table 2: Reported outcomes

\begin{tabular}{|l|c|c|c|c|}
\hline Outcomes & Positive & Neutral & Mixed & Not reported \\
\hline Level 1 - Reaction & 25 & 0 & 7 & 14 \\
\hline $\begin{array}{l}\text { Level 2a - Perceptions \& } \\
\text { attitudes }\end{array}$ & 14 & 1 & 11 & 20 \\
\hline $\begin{array}{l}\text { Level - 2b Knowledge \& } \\
\text { skills }\end{array}$ & 19 & 1 & 6 & 20 \\
\hline $\begin{array}{l}\text { Level 3 - Behavioural } \\
\text { change }\end{array}$ & 15 & 0 & 5 & 26 \\
\hline $\begin{array}{l}\text { Level - 4a organisational } \\
\text { practice }\end{array}$ & 11 & 1 & 2 & 35 \\
\hline $\begin{array}{l}\text { Level 4b - Patient/client } \\
\text { care }\end{array}$ & 9 & 1 & 1 & \\
\hline
\end{tabular}

Overall, as this table indicates, more positive outcomes are reported than mixed, neutral or negative outcomes. This is especially noticeable for the learners' reaction to IPE ( 25 studies, $54 \%$ ) and changes in knowledge and skills (19 studies, 41\%). In contrast, only 13 studies (28\%) reported on outcomes related to changes in organisational practice and 10 studies (22\%) on changes to patient/client care. Collectively, these studies report almost twice as many changes (positive or mixed) related to learner reactions, shifts in perceptions/attitudes and/or knowledge/skills ( 82 reported outcomes) than they report changes to behaviour, service delivery or patient/benefit (43 reported outcomes).

Nineteen of the IPE studies (41\%) reported mixed outcomes (positive, neutral and/or negative), with studies reporting mixed changes to learner attitudes/perceptions ( $n=11$, $24 \%$ ) the most frequent. None of the studies reported negative outcomes alone, these were always part of a mixed set of outcomes. In contrast, there were far fewer instances of studies reporting neutral outcomes (4 studies, $9 \%$ ).

Studies typically reported multiple outcomes - usually 2 to 3 outcomes (e.g. Solberg et al. 1998; Horbar et al. 2002; Bradley et al. 2009; Hobgood et al. 2010; Anderson \& Thorpe 2014). In general, the studies involving undergraduate students reported outcomes linked to levels $1,2 a$ or $2 b$, while those involving qualified practitioners reported outcomes linked to levels $3,4 a$ and $4 b$. This difference of reporting outcomes is not surprising, as the time gap between undergraduates receiving their IPE and them qualifying as practitioners presents challenges with reporting outcomes at levels $3,4 a$ and $4 \mathrm{~b}$. However, four undergraduate IPE studies did report outcomes at these levels (Dienst \& Byl 1981; Reeves \& Freeth 2002; Anderson \& Thorpe 2014; Shiyanbola et al 2014). In addition, one study reporting on a postgraduate course for mental health practitioners reported outcomes across the six levels (Carpenter et al. 2007). 
Reaction, perceptions/attitudes and knowledge/skills outcomes

Table 2 shows that 32 of the studies (65\%) reported changes to level 1 - changes to learner reactions ( 25 reported positive and seven reported mixed outcomes). This type of outcome typically focused on learner's feedback related to: valuing/supporting the use of IPE (e.g. Crutcher et al. 2004; Bradley et al. 2009; Hollenberg et al. 2009), reporting satisfaction with their IPE involvement (e.g. Curran et al. 2007; Fletcher et al. 2014) or reporting that their IPE was enjoyable or rewarding (e.g. Reeves 2000; Quinn et al. 2008).

Of the 22 studies (48\%) which reported at level $2 a$ - changes to learners' attitudes/perceptions, 14 studies reported positive, seven studies reported mixed and one study reported neutral outcomes. In relation to these studies, for example, McFadyen et al. (2010) employed a longitudinal controlled trial design and gathered IPE attitudinal data with the use of two pre-validated surveys with over 500 students in either an intervention group $(n=313)$ or control group $(n=260)$. The authors reported that over a period of four years IPE helped generate and also sustained a range of positive attitudes towards IPE. In contrast, Pollard et al. (2006), who also used a controlled longitudinal design to gather pre-validated survey data from undergraduate student attitudes and perceptions (468 student in an intervention group, 250 students in a comparison group) reported a more mixed set of outcomes at this level. These authors found that students reported a negative shift in attitudes to IPE and interaction during their undergraduate course, but there was an improvement in attitudes to their own professional relationships at qualification. However, in a later paper, Pollard \& Miers (2008) found that after 9 to 12 months qualification, former students reported that IPE did produce some longer-term positive attitudes toward collaborative working.

Twenty-six studies (56\%) reported outcomes at level $2 \mathrm{~b}$ - changes to knowledge/skills (19 reported positive outcomes, six reported mixed outcomes and one reported neutral outcomes). In general, across the IPE studies, knowledge and skills were evaluated by use of interviews or surveys reporting self-assessment of such changes (e.g. Barber et al. 1997; Reeves \& Freeth 2002; Quinn et al. 2008; Hollenberg 2009; Richardson et al. 2010, Robben et al. 2012; Paquette-Warren 2014). However, self-report data is a weak measure of knowledge and skills change given an individual's inability to assess such gains accurately. Examples of where studies gather more robust data at this level can be seen in Carpenter et al. (2006) who gathered interview data and scores from a self-rated core competency scale which were then triangulated with formally assessed knowledge and skills obtained from course assignments. Also, Hobgood et al (2010) assessed this level of outcome in a simulated IPE session through the use of a pre/post intervention teamwork knowledge test which was triangulated with observations of students' teamwork skills.

\section{Behavioural, organisational and patient/client outcomes}

Table 2 shows that 20 studies (43\%) reported changes in individual participants' behaviour (level 3) following their participation in an IPE course. Of these studies, 15 reported positive outcomes (e.g. Morey et al. 2002; Mu et al. 2004; Kilminster et al. 2004; Curran et al 2007; Hollenberg et al. 2009) and five mixed (positive/neutral) outcomes (e.g. LeFlore at al. 2009; Paquette-Warren et al. 2014). Studies which reported these types of outcomes tended to continue to employ mainly self-reported perceptions of changes. For example, PaquetteWarren et al. (2014) gathered qualitative interviews with participants to provide 
perceptions of behavioural change following their experiences of interprofessional learning during a quality improvement initiative for primary care teams. Self-reported changes to behaviours need to be treated with caution, as individuals are widely recognised as being poor in self-assessment (e.g. Davis et al., 2006). As a result, such reports must be regarded as weak approaches to measuring behavioural change. Although a more rigorous approach was provided by Watts et al (2007) who employed a well-validated scale (Team Climate Inventory) to detect behaviour changes at three time-points (baseline, four months and eight months) in their evaluation of a work-based IPE initiative for a range of different clinical teams, these data are still based on self-assessed reports, so cannot offer actual changes to behaviours. In contrast, there were a small number of studies which gathered more robust data at this level. For instance, Morey et al. (2002) used robustly developed rating scales and trained raters to assess team behaviours and technical skills in emergency departments. Cooke et al. (2003) also employed researchers' observations in their study of medical and nursing students working with simulated patients to explore breaking bad news.

Fourteen studies (30\%) reported changes to organisational practice - level $4 a$. These consisted of 11 studies that reported positive outcomes (Dienst \& Byl 1981; Solberg et al. 1998; Horbar et al. 2001; Shafer et al. 2002; Carpenter et al 2006; Curran et al 2007; Watts et al. 2007; Hollenberg et al. 2009; Brynes et al. 2012; Slater et al. 2012; Anderson \& Thorpe 2014), two studies that reported mixed outcomes (Ketola et al. 2000; Paquette-Warren et al. 2014) and one study that reported neutral outcomes (Fuhrman et al. 2009). Studies at this level involved a range of different types of IPE experiences, including qualified practitioners undertaking service quality improvement (QI) initiatives (e.g. Shafer et al. 2002; Paquette-Warren et al. 2014 ), delivery of continuing IPE courses (e.g. Hollenberg et al. 2009; Slater et al. 2012) and practice-based facilitators (Watts et al. 2007; Brynes et al. 2012). These papers reported that IPE was effective at improving service delivery across a range of areas such as, illness prevention, patient screening, referrals between agencies and safety practices (e.g. Horbar et al. 2001; Shafer et al. 2002; Curran et al. 2007; Slater et al. 2012). While two studies reported a mixture of positive and neutral outcomes (Ketola et al. 2000; Paquette-Warren et al. 2014) associated with their Ql initiatives, Fuhrmann et al. 2009) found simulated IPE for physicians and nurses based on general wards at a Danish hospital did not have any effect on identifying and recording patient risk.

Of the 11 studies (24\%) which reported changes to level $4 \mathrm{~b}$ - patient/client care outcomes, nine studies reported positive outcomes (Dienst \& Byl 1981; Horbar et al. 2001; Reeves \& Freeth 2002; Shafer et al. 2002; Carpenter et al. 2006; Visser \& Wysmans 2010; Lineker et al. 2012; Anderson \& Thorpe 2014; Shiyanbola et al. 2014), one study reported mixed outcomes (Morey et al. 2002) and one study reported neutral outcomes (Fuhrmann et al 2009). Measurement for studies reporting outcomes at this level were clinical outcomes such as mortality rates, recorded clinical errors or patient length of stays (Horbar et al. 2001; Morey et al. 2002; Fuhrmann et al. 2009) and less robust measures such as patient satisfaction scores (Visser \& Wysmans 2010; Lineker et al. 2012). While most of these studies involved the delivery of IPE to practitioners, often in clinical settings, four IPE studies did involve undergraduate students working together to deliver care to patients (Dienst \& Byl 1981; Reeves \& Freeth 2002; Shiyanbola et al. 2014; Anderson \& Thorpe 2014). For example, Reeves \& Freeth (2002) reported that patients on an interprofessional training 
ward were very satisfied with the care they received. Also, Shiyanbola et al. (2014) reported improvements to patents' blood pressure and cholesterol levels after student teams working in a clinical placement provided them with diabetes education.

\section{Discussion}

Given the sustained increase in interest in IPE since the publication of the previous review, we undertook an update to understand how the nature of the IPE evidence has evolved in the intervening years. Importantly, this update was undertaken to synthesise the best available contemporary evidence to help shape future design, delivery and evaluation of IPE. As described above, the updated review located 25 new studies that were added to the 21 existing studies resulting in a total of 46 studies. Based on these studies we undertook a quantitative and qualitative analysis and synthesis. The 3P model was again used as an analytical tool to help identify key aspects of context (presage), related mechanisms (IPE teaching and learning process) and associated outcomes (IPE products) reported within the studies.

As presented earlier, key presage (context) factors affecting the delivery of IPE continued to be national policy calls for more collaborative working linked to addressing patients' complex needs, reducing clinical error and improving safety. However, this update found that IPE can continue to be impeded by a number of contextual factors such as space and timetabling of other profession-specific learning activities. As a result, organisational support from local IPE leaders and senior management was regarded as central to the successful implementation and sustainability of IPE. A lack of this form of support could seriously jeopardise the longer term viability of IPE. In addition, while 30 of the studies did acknowledge external funding for their work, little detail was provided about the effect of funding issues as barriers in relation to designing and implementing IPE. Clearly though, external funding in these studies has supported the implementation of a range of IPE activities underpinned by rigorous evaluation. Therefore, while explicit mention of funding as an enabler or a barrier to IPE was overlooked, budgetary factors are influential in enabling IPE evaluations to provide some useful empirical accounts about the effects of this form of health professions education. Further, empirical work is also needed describing the costs and value of IPE, as studies reporting the output of such economic analyses continue to be overlooked (Walsh et al. 2014).

Another key element reported in the studies linked to the wider context within which IPE is delivered related to professional participation and learner numbers. As outlined above, IPE regularly involved a wide variety of learners from different professional groups who collectively made up large cohorts. As a result, one needs to be aware of the degree of complexity this generates to the implementation of IPE. In contrast, other contextual issues such as geography and demography were not reported in the 46 studies.

In relation to facilitator characteristics, the expertise of the facilitators involved in delivering the interprofessional learning was reported as a continued key factor in students' experience. To ensure a high quality facilitation experience, facilitator preparation and support was also reported as crucial to ensure interprofessional learning was delivered in an effective manner. Of the included studies, factors such as prior experiences, age and gender were seen as influential learner characteristics that could affect their perceptions/attitudes 
toward IPE. Learner conceptions of IPE and their willingness to participate can also be affected by other issues such as professional background as well as negative stereotypes and notions of status/hierarchy.

In respect to process factors reported in the update, unlike the previous review there was more limited attention placed on reporting facilitation processes. However, there was a continued focus on IPE facilitators coaching interprofessional learners. In addition, the update found some evidence of IPE facilitators extending their role during interprofessional simulation activities. The updated review also found issues of authenticity from the learning experience and customisation continued to be of importance. Similarly, there was some continued attention placed on the use of shared interprofessional reflection and informal learning opportunities. However, unlike the previous review, the newer studies contained less student involvement in the development of their IPE.

Like the previous review, the results from this update continue to show far more positive than neutral or mixed outcomes reported in the studies. Based on the 46 studies, the evidence suggests that, in general, learners responded well to the IPE, their attitudes/perceptions of one another improve and they gain knowledge and skills necessary for collaborative practice. Whereas the previous review indicated that changes in perceptions and attitudes were more likely to show mixed results than the other outcomes, this has shifted a little in the newer papers in favour of the reporting of more positive outcomes. Also, while more positive changes were reported for behaviour, organisational practice and the delivery of patient/client care than in the previous review, there was far less evidence of change for these levels in the newer papers.

However, one needs to provide a word of caution with the nature of this evidence. Given the reliance on self-reported data in many of the studies, the extent of actual change may well be less than what was reported by IPE participants linked largely to their perceptions of change. Mindful of these (and other) limitations to the IPE evidence base, Reeves et al. (2015) recently published guidance for improving the quality of IPE studies to support evaluation teams, in their future work, to generate more rigorous evidence.

In comparison with the previous review, this update revealed that the inclusion of 25 new studies, in general, provided empirical support for presage, process and product factors identified in the previous review. This finding indicates that there appears to be a continued focus in the evaluation of IPE on investigating a relatively small, bounded set of phenomenon linked to IPE context, learner characteristics and teaching/learning processes. This focus also extends to reporting a similar range of outcomes - mostly linked to levels 1 , $2 a$ and $2 b$ of the expanded Kirkpatrick model (Barr et al. 2005). Given this empirical focus of the studies, the imbalance of reporting of the different 3P factors within the previous review linked specifically to teacher (facilitator) characteristics continues, with little evidence reported on this facet of presage. This oversight contrasts with the IPE literature which expanded in the past few years with more qualitative studies reporting on facilitation (e.g. Egan-Lee et al 2011; Evans et al. 2014). However, at present, the quality of this emerging work did not meet the quality assessment criteria used for this review. Building upon this discussion, Box 2 goes on to present a series of implications linked to this review. 
While the authors followed best practices in systematic review techniques while undertaking this updated review, there are inevitably limitations. Our search was limited by excluding the grey literature, only including studies published in English or French and not searching the reference lists of included papers. As a result, it is possible that we may have missed a small number of potential IPE studies. In addition, assessing the methodological quality of any study is ultimately based on a subjective judgement, even if using a standardised approach to quality assessment (as we did), ultimately such decisions are still based on an individual reviewer's interpretation. Finally, we acknowledge the well-known publication bias within the health sciences literature, which may mean that rigorous IPE studies reporting negative outcomes struggle for publication.

\section{Box 2: Key review implications}

- Faculty development is critical to prepare and support IPE facilitators in order to deliver effective IPE.

- IPE developers and facilitators should be aware that the learners' view of IPE is related to multiple factors which can affect their engagement in this type of education.

- Learning about being interprofessional in a context that reflects the students' current or future practice is important for effective learning.

- In order to enhance learning experiences for students, educators should consider underpinning their IPE courses and programmes with the explicit use of educational theories.

- More studies are needed which develop a firmer understanding of the teaching and learning processes involved in the delivery of effective IPE.

- Future empirical work is needed to begin measuring economic elements of IPE in relation to its cost and value.

- Funding should be sought to undertake rigorous IPE studies which can measure the effects of IPE on behaviours, organisational change as well as the delivery of care. Where possible, multi-institutional studies, should be considered.

- There is a need to develop robust use of tools of measurement for IPE, especially tools aimed at measuring how IPE may affect individual and organisational behaviour.

- A wider use of models for measuring the processes and products of IPE (e.g. Kirkpatrick model, 3P model, realistic evaluation) would generate more robust IPE studies which could also be used for comparative analysis to strengthen the IPE evidence base. 


\section{Conclusions}

The previous review identified 21 high quality IPE studies, and this update located a further 25 studies to form a complete data set of 46 high quality studies. As presented above, the update offered an insight into the nature of IPE and its evolution since the publication of the previous review in 2007. This update has provided evidence that key context and process factors reported in the previous review continue to have resonance on the delivery of IPE. In addition, the 25 newer studies have extended the volume of reported outcomes indicating that IPE can affect change across a number of outcome levels.

In updating this review, we have described the growth of IPE evidence. It is anticipated this work will help IPE curriculum planners and educators make informed judgements about the use of different types of IPE initiatives delivered in a variety of contexts around the globe. In addition, it is hoped that reporting the evolving IPE evidence will provide useful information to other IPE stakeholders (i.e. managers, policy makers, practitioners) related to the differing effects of IPE on learner satisfaction, attitudes/perceptions, collaborative knowledge/skills and behaviours, and ultimately on improving service delivery and patient/client care.

\section{Notes on Contributors}

To be added

\section{Acknowledgements}

We would like to acknowledge Dr Ferruccio Pelone for his help and guidance with searching the literature for this review. We would also like to acknowledge our respective institutions for their support in completing the review. Finally, we would like to thank the BEME editorial team for their advice in finalising this work.

\section{Declaration of interest}

The authors have no interests to declare.

\section{References}

Included studies from the 2007 review

Barber G, Borders K, Holland B, Roberts K. 1997. Life Span Forum: an interdisciplinary training experience. Gerontology \& Geriatrics Educ 18:47-59.

Carpenter J. 1995. Interprofessional education for medical and nursing students: evaluation of a programme. Med Educ 29:265-272.

Carpenter J, Hewstone M. 1996. Shared learning for doctors and social workers: evaluation of a programme. Br J Soc Work 26:239-257.

Cooke S, Chew G, Boggis C, Wakefield A. 2003. I never realised that doctors were into feelings too': changing student perceptions through interprofessional education. Learn Health Soc Care 2:137-146. 
Crutcher R, Then K, Edwards A, Taylor K, Norton P. 2004. Multiprofessional education in diabetes. Med Teach 26:435-443.

Dienst ER, Byl N. 1981. Evaluation of an educational program in health care teams. J Comm Health 6:282-298.

Horbar JD, Rogowski J, Plsek PE, Delmore P, Edwards WH, Hocker J, Kantak AD, Lewallen P, Lewis W, Lewit E, McCarroll CJ, Mujsce D, Payne NR, Shiono P, Soll RF, Leahy K, Carpenter JH. 2001. Collaborative quality improvement for neonatal intensive care. NIC/Q Project Investigators of the Vermont Oxford Network. Pediatrics 107:14-22.

Ketola E, Sipila R, Makela M, Klockars M. 2000. Quality improvement programme for cardiovascular disease risk factor recording in primary care. Qual Health Care 9:175-180.

Kilminster S, Hale C, Lascelles M, Morris P, Roberts T, Stark P, Sowter J, Thistlethwaite J. 2004. Learning for real life: patient focused interprofessional workshops offer added value. Med Educ 38:717-726.

Morey JC, Simon R, Jay GD, Wears RL, Salisbury M, Dukes KA, Berns SD. 2002. Error reduction and performance improvement in the emergency department through formal teamwork training: evaluation results of the MedTeams project, Health Ser Res 37:15531581.

Morison S, Boohan M, Jenkins J, Moutray M. 2003. Facilitating undergraduate interprofessional learning in healthcare: comparing classroom and clinical learning for nursing and medical students. Learn Health Soc Care 2:92-104.

Mu K, Chao C, Jensen G, Royeen C. 2004. Effects of interprofessional rural training on students' perceptions of interprofessional health care services. J Allied Health 33:125-131.

Nash A, Hoy A. 1993. Terminal care in the community-an evaluation of residential workshops for general practitioner/district nurse teams. Palliative Med 7:5-17.

Pollard K, Miers M, Gilchrist M. 2005. Second year scepticism: prequalifying health and social care students' midpoint self-assessment, attitudes and perceptions concerning interprofessional learning and working. J Interprof Care 19:251-268.

Ponzer S, Hylin U, Kusoffsky A, Lauffs M, Lonka K, Mattiasson A, Nordstrom G. 2004. Interprofessional training in the context of clinical practice: goals and students' perceptions on clinical education wards. Med Educ 38:727-736.

Reeves S. 2000. Community-based interprofessional education for medical, nursing and dental students. Health Soc Care Comm 4:269-276.

Reeves S, Freeth D. 2002. The London training ward: an innovative interprofessional learning initiative. J Interprof Care 16:41-52. 
Shafer MA, Tebb KP, Pantell RH, Wibbelsman CJ, Neuhaus JM, Tipton AC, Kunin SB, Ko TH, Schweppe DM, Bergman DA. 2002. Effect of a clinical practice improvement intervention on Chlamydial screening among adolescent girls. JAMA 288:2846-2852.

Solberg LI, Kottke TE, Brekke ML. 1998. Will primary care clinics organize themselves to improve the delivery of preventive services? A randomized controlled trial. Preventive Med 27:623-631.

Tucker K, Wakefield A, Boggis C, Lawson M, Roberts T, Gooch J. 2003. Learning together: clinical skills teaching for medical and nursing students. Med Educ 37:630-637.

Tunstall-Pedoe S, Rink E, Hilton S. 2003. Student attitudes to undergraduate interprofessional education. J Interprof Care 17:161-172.

Included studies from the updated review

Ammentorp J, Sabroe S, Kofoed P.E, Mainz J. 2007. The effect of training in communication skills on medical doctors' and nurses' self-efficacy A randomized controlled trial. Patient Ed \& Counselling 66:270-277

Anderson E.S, and Thorpe L.N. 2014. Students improve patient care and prepare for professional practice: An interprofessional community-based study. Med Teach 36:495-504

Bradley P, Cooper S, Duncan F. 2009. A mixed-methods study of interprofessional learning of resuscitation skills. Med Ed 43:912-922

Byrnes V, O'Riordan A, Schroder C, Chapman C, Medves J, Paterson M, Grigg R. 2012. South Eastern Interprofessional Collaborative Learning Environment (SEIPCLE): Nurturing Collaborative Practice, J Res Interprof Prac \& Ed, 2.2:169-186

Carpenter J, Barnes D, Dickinson C, Wooff. D. 2006. Outcomes of interprofessional education for Community Mental Health Services in England: The longitudinal evaluation of a postgraduate programme, J Interprof Care, 20:145 - 161

Curran V, Sergeant J, Hollett A. 2007. Evaluation of Interprofessional Continuing Professional Development Initiative in Primary Health Care, J Cont Ed Health Professions, 27:241-252

Fletcher J, King K, Christo J, Machlin A, Bassilios B, Blashki G, Gibbs C, Nicholas A, Pirkis J. 2014. An evaluation of an Australian initiative designed to improve interdisciplinary collaboration in primary mental health care, Eval Prog Planning, 45:29-41

Fuhrmann L, Perner A, Klausen T, Østergaard D, Lippert, A. 2009. The effect of multiprofessional education on the recognition and outcome of patients at risk on general wards, Resus, 80: 1357-1360

Hobgood C, Sherwood G, Frush K, Hollar D, Maynard L, Foster B, Sawning S, Woodyard D, Durham C. 2009. Teamwork training with nursing and medical students: does the method 
matter? Results of an interinstitutional, interdisciplinary collaboration, Qual Saf Health Care, 19:1-6

Hollenberg E, Reeves S, Beduz M.A, Jeffs L, Kwan D, Lee J, Lowe M, Merkley J, Sinclair L, Tassone M, Oandasan I. 2009. "Mainstreaming" Interprofessional Education within Hospital Settings: Findings from a Multiple Case Study, J Res Interprof Prac Ed, 1.1:10-23

Just J.M, Schnell M.W, Bongartz M, Schulz C. 2010. Exploring Effects of Interprofessional Education on Undergraduate Students' Behaviour: A Randomized Controlled Trial, J Res Interprof Prac Ed, 1.3:183-199

LeFlore J.L and Anderson M. 2009. Alternative Educational Models for Interdisciplinary Student Teams, Simulation in Healthcare, 4:135-142

Lineker S.C, Husted J.A, Brown S. 2012. Influence of Discipline of Provider and Model of Care on an Arthritis Educational Intervention in Primary Care, Arthritis Care \& Research, 64:424-433

McFadyen M.K, Webster V.S, Maclaren W.S, O'Neill M.A. 2010. Interprofessional attitudes and perceptions: Results from a longitudinal controlled trial of pre-registration health and social care students in Scotland, Journal Interprof Care, 24:549-564

Nisbet G, Hendry G.D, Rolls G, Field M.J. 2008. Interprofessional learning for prequalification health care students: An outcomes-based evaluation, Journal Interprof Care, 22:57-68

Paquette-Warren J, Roberts S, Fournie M, Tyler M, Brown J, Harris S. 2014. Improving chronic care through continuing education of interprofessional primary healthcare teams: a process evaluation, J Interprof Care, 28:232-238

Pollard K.C, Miers M.E, Gilchrist M, Sayers A. 2006. A comparison of interprofessional perceptions and working relationships among health and social care students: the results of a 3-year intervention, Health \& Social Care Community, 14:541-552

Pollard K.C and Miers M.E. 2008. From students to professionals: Results of a longitudinal study of attitudes to pre-qualifying collaborative learning and working in health and social care in the United Kingdom, J Interprof Care, 22:399-416

Quinn K, Hudson P, Ashby M, Thomas K. 2008. "Palliative Care: The Essentials": Evaluation of a Multidisciplinary Education Program, J Palliative Medicine, 11:1122-1129

Robben S, Perry M, Van Nieuwenhuijzen L, Van Achterberg T, Rikkert M, Schers $H$, Heinen M, Melis R. 2012. Impact of Interprofessional Education on Collaboration Attitudes, Skills, and Behavior Among Primary Care Professionals, J Cont Ed Health Professions, 32:196-204 
Richardson R, Letts L, Childs A, Semogas D, Stavness C, Smith B, Guenter D, Price D. 2010. Development of a Community Scholar Program: An Interprofessional Initiative, J Physical Therapy Ed, 24:37-43

Shiyanbola O, Randall B, Lammers C, Hegge K.A, Anderson M. 2014. Impact of an Interprofessional Diabetes Education Model on Patient Health Outcomes: A Longitudinal Study, J Research Interprof Prac and Ed, 4.2:2-21

Slater B, Lawton R, Armitage G, Bibby J, Wright, J. 2012. Training and Action for Patient Safety: Embedding interprofessional education for patient safety within an improvement methodology, J Cont Ed Health Professions, 32:80-89

Visser A, and Wysmans M. 2010. Improving patient education by an in-service communication training for health care providers at a cancer ward: Communication climate, patient satisfaction and the need of lasting implementation, Patient Ed \& Counsel, 78:402408

Watts F, Lindqvist S, Pearce S, Drachler M, Richardson B. 2007. Introducing a postregistration interprofessional learning programme for healthcare teams. Med Teac 29:443449.

\section{Other references}

Abu-Rish E, Kim S, Choe L et al. 2012. Current trends in interprofessional education of health sciences students: A literature review. J Interprof Care; 26(6):444-451.

Bandura A. Health promotion by social cognitive means. Health Educ Behav. 2004; 31(2):143-164.

Bandura A. Self-efficacy: toward a unifying theory of behavioural change. Psychol Rev 1977;84: 191-215.

Barr H, Koppel I, Reeves S, Hammick M, Freeth D. 2005. Effective Interprofessional Education: Assumption, Argument and Evidence. Blackwell, London.

Brandt B, Lutfiyya N, King J et al. 2014. A scoping review of interprofessional collaborative practice and education using the lens of the triple aim. J Interprof Care; 28(5):393-399

Bridges, D.R, Davidson, R.A, Soule Odegard, P, Maki, I.V. and Tomkowiak, J. 2011. Interprofessional collaboration: three best practice models of interprofessional education, $J$ Contin Ed Health Prof, 29(3): 161-167.

CAIPE 2002. Interprofessional education: a definition. CAIPE, London.

Clarke P. 2005. What would a theory of interprofessional education look like? some suggestions for developing a theoretical framework for teamwork training. J Interprofessional Care; 20(6): 577-589. 
Davis D, Mazmanian P, Fordis M, Van Harrison R, Thorpe K, Perrier P. 2006. Accuracy of Physician Self-assessment Compared With Observed Measures of Competence: A Systematic Review. JAMA. 2006;296(9):1094-1102.

Egan-Lee E, Baker L, Dematteo D, Hollenberg E, Tobin S, Reeves S. 2011. Neophyte facilitator experiences of interprofessional education: implications for faculty development. J Interprof Care; 25:333-338.

Evans S, Knight T, Sønderlund A \& Tooley G. 2014. Facilitators' experience of delivering asynchronous and synchronous online interprofessional education. Med Techer; 36:12, 1051-1056.

Frenk, J., Chen, L., Bhutta, Z., Cohen, J., Crisp, N., Evans, T. et al. 2010. Health professionals for a new century: transforming education to strengthen health systems in an interdependent world. The Lancet, 376: 1923-1958.

Fung L, et al. 2015. Impact of crisis resource management simulation-based training for interprofessional and interdisciplinary teams: A systematic review. J Interprof Care; 29: 433444.

Hammick M, Freeth D, Koppel I, Reeves S, Barr H. 2007. A best evidence systematic review of interprofessional education. Med Teacher; 29:735-751.

Institute of Medicine. 2015. Institute of Medicine. Measuring the impact of interprofessional education on collaborative practice and patient outcomes. Washington, D.C.: The National Academies Press.

Kent, F, Keating, J. 2013. Patient Outcomes from an interprofessional student led clinic in primary care, Journal of Interprofessional Care, 27(4), pp. 336-338

Knowles M. 1975. Self-directed Learning: a Guide for Learners and Teachers. Chicago, Follett Publishers

Kolb D. 1984. Experiential learning. Englewood Cliffs, NJ: Prentice-Hall.

Luke, R, Solomon, P, Baptiste, S, Hall, P, Orchard, C, Ruckholm, E \& Carter, L. 2010. Online interprofessional health sciences education: From theory to practice, J Interprof Care, 28:110-115

Makino T, Shinozaki H, Hayashi K, Lee B, Matsui H, Kururi N, Kazama H, Ogawara H, Tozato F, Iwasaki K, Asakawa Y, Abe Y, Uchida Y, Kanaizumi S, Sakou K, Watanabe H. 2013. Attitudes toward interprofessional healthcare teams: A comparison between undergraduate students and alumni. J Interprof Care; 27:261-268.

Mays N, Pope C, Popay J. 2005. Systematically reviewing qualitative and quantitative evidence to inform management and policy-making in the health field. J Health Serv Res Policy; 10(1):6-20. 
Palaganas, J.C, Epps, C. and Raemer, D.B. 2014. History of simulation-enhanced interprofessional education, J Interprof Care, 28(2), pp. 110-115

Reeves S, Boet S, Zierler B, Kitto S. 2015. Interprofessional Education and Practice Guide No. 3: Evaluating interprofessional education. J Interprof Care; 29:305-312.

Reeves S, Perrier L, Goldman J, Freeth D, Zwarenstein M. 2013. Interprofessional education: effects on professional practice and healthcare outcomes (update). Cochrane Database of Systematic Reviews 2013, Issue 3. Art. No.: CD002213.

Schön D (1983) The Reflective Practitioner: how professionals think in action London: Temple Smith.

Vygostsky LM. 1978. Mind in Society. Cambridge: Harvard University Press.

Walsh K, Reeves S, Maloney S. 2014. Exploring issues of cost and value in professional and interprofessional education. J Interprof Care; 28(6): 493-494

World Health Organization. 2010. Framework for action on interprofessional education and collaborative practice. WHO, Geneva. 